\title{
RESPONSES OF A BACTERIAL PATHOGEN TO PHOSPHORUS LIMITATION OF ITS AQUATIC INVERTEBRATE HOST
}

\author{
Paul C. Frost, ${ }^{1,4}$ Dieter Ebert, ${ }^{2}$ and Val H. Smith ${ }^{3}$ \\ ${ }^{1}$ Department of Biology, Trent University, Peterborough, Ontario K9J 7 B8 Canada \\ ${ }^{2}$ Universität Basel, Zoologisches Institut, Vesalgasse 1, 4051 Basel, Switzerland \\ ${ }^{3}$ Department of Ecology and Evolutionary Biology, University of Kansas, Lawrence, Kansas 66045 USA
}

\begin{abstract}
Host nutrition is thought to affect the establishment, persistence, and severity of pathogenic infections. Nutrient-deficient foods possibly benefit pathogens by constraining host immune function or benefit hosts by limiting parasite growth and reproduction. However, the effects of poor elemental food quality on a host's susceptibility to infection and disease have received little study. Here we show that the bacterial microparasite Pasteuria ramosa is affected by the elemental nutrition of its aquatic invertebrate host, Daphnia magna. We found that high food carbon:phosphorus (C:P) ratios significantly reduced infection rates of Pasteuria in Daphnia and led to lower within-host pathogen multiplication. In addition, greater virulent effects of bacterial infection on host reproduction were found in Daphniaconsuming P-deficient food. Poor Daphnia elemental nutrition thus reduced the growth and reproduction of its bacterial parasite, Pasteuria. The effects of poor host nutrition on the pathogen were further evidenced by Pasteuria's greater inhibition of reproduction in P-limited Daphnia. Our results provide strong evidence that elemental food quality can significantly influence the incidence and intensity of infectious disease in invertebrate hosts.
\end{abstract}

Key words: bacterial pathogen; Daphnia; ecological stoichiometry; elemental imbalance; infectious disease; life-history; Pasteuria ramosa.

\section{INTRODUCTION}

Many organisms are strongly affected by the mineral content of their food (Sterner and Elser 2002, Frost et al. 2006). Elemental deficiencies place severe limits on vital metabolic activities directly linked to organismal fitness, such as growth and reproduction. In addition, nutritional stress alters physiological processes involved in the acquisition, storage, and release of dietary elements in all types of organisms (Frost et al. 2005). Pathogens may experience similar elemental constraints on their metabolism if their resource supply is tightly linked to the host's diet and their host is consuming food of poor elemental quality. If so, low mineral content in a host's diet could affect host-pathogen dynamics by constraining pathogen growth and reproduction. Alternatively, elemental constraints on the host could limit its ability to generate and maintain immune defenses (Calder and Jackson 2000, Kegley et al. 2001, Frost et al. 2005), thereby leading to enhanced growth and reproduction by invading pathogens. In addition, direct effects of poor nutrition on host growth and survival may reduce parasite transmission or alter other epidemiological processes. However, the effects of elemental food quality on host interactions with pathogenic organisms remain largely unexamined.

Manuscript received 8 March 2007; revised 7 September 2007; accepted 11 October 2007. Corresponding Editor: R. W. Sterner.

${ }^{4}$ E-mail: paulfrost@ trentu.ca
The effects of pathogens on host fitness (i.e., virulence) could also be moderated by variations in the elemental food quality of the host's diet. If pathogen proliferation is limited by elemental constraints created by poor host nutrition, then the consequent effects of infection on host growth and reproduction could be reduced. Conversely, elemental constraints on pathogens could result in their relatively greater sequestration of growth-limiting resources, leaving a smaller resource pool available for host metabolism. If so, poorly nourished hosts would experience enhanced virulence from their nutrient-limited pathogens. Greater virulence could also arise if poor nutrition limits the host's abilities to repair damage that occurs during the growth and replication of the pathogen population.

In this study, we tested whether changes in elemental food quality (indexed here by the molar carbon: phosphorus [C:P] ratio) alter host-parasite interactions using the aquatic invertebrate Daphnia magna and the bacterial pathogen Pasteuria ramosa. Under conditions of high food quantity and quality, previous research has shown Pasteuria to be highly effective at infecting Daphnia (Regoes et al. 2003). Pasteuria infections in Daphnia are generally nonreversible and greatly reduce daphnid fitness (Ebert 2005). This pathogen renders Daphnia completely sterile, causes gigantism, and eventually produces millions of infective spores within the daphnid body (Ebert 2005). Infective spores are typically released into the environment after the death of the Daphnia, where they remain dormant until they find 
TABle 1. Elemental composition (C:N, N:P, and C:P ratios) of food algae (Scenedesmus acutus) grown under contrasting $\mathrm{P}$ supply and dilution rates.

\begin{tabular}{ccccr}
\hline \hline $\begin{array}{c}\text { Media P } \\
(\mu \mathrm{mol} \mathrm{P} / \mathrm{L})\end{array}$ & $\begin{array}{c}\text { Dilution } \\
\left(\text { day }^{-1}\right) \dagger\end{array}$ & C:N & N:P & C:P \\
\hline 55 & 0.50 & 7.33 & 9.00 & 66 \\
55 & 0.50 & 7.39 & 13.3 & 86 \\
35 & 0.40 & 8.08 & 31.9 & 117 \\
22 & 0.20 & 7.81 & 26.9 & 210 \\
17 & 0.20 & 11.2 & 34.1 & 330 \\
17 & 0.20 & 8.62 & 46.0 & 363 \\
13 & 0.20 & 11.5 & 48.6 & 561 \\
8.0 & 0.10 & 11.4 & 83.7 & 772 \\
6.0 & 0.10 & 9.86 & 89.9 & 909 \\
4.0 & 0.10 & 8.78 & 103 & 1257 \\
\end{tabular}

Note: Representative data from cultures receiving different $\mathrm{P}$ supplies are shown.

$\uparrow$ The dilution rate was the proportion of the growth medium that was replaced on a daily basis.

a new host. Pasteuria's resting spores appear to be a main mode of infection, as there is no transfer of infection from host mother to offspring (Ebert 2005). See Ebert (2005) for additional details of Pasteuria's lifehistory and its interactions with its daphnid hosts. Here, we examined whether components of bacterial fitness, measured in terms of infection rate and spore production, would be altered by the C:P nutrition of Daphnia. In addition, we assessed the extent to which Daphnia reproductive losses due to infection were affected by host food C:P ratios.

\section{Methods}

\section{Infection rate experiments}

We examined the infection rate (in terms of the percentage of individuals infected by a given dose of bacterial spores) of laboratory-grown Daphnia raised on food having different $\mathrm{C}: \mathrm{P}$ ratios $(100-800)$, a range typical of that in natural lakes (Guildford and Hecky 2000). We first collected $\sim 250$ daphnid neonates $(<1$ day old) that were born to second-generation clonal sisters. Throughout the experiment, all Daphnia were raised individually in $20 \mathrm{~mL}$ (days $0-4$ ) and $40 \mathrm{~mL}$ (day 4 and thereafter) of filtered and autoclaved river water from the Ontonobee River near Trent University. Neonates were assigned into one of six food P-levels, with each food type receiving between 30 and 35 animals. Different food C:P ratios were created by mixing a single species of algae (Scenedesmus acutus, University of Toronto Culture Collection 10) harvested from semicontinuous cultures grown under contrasting P-supply rates. Algal cultures were diluted daily with COMBO, an artificial algal growth medium (Kilham et al. 1998) and grown under a constant temperature $\left(20^{\circ} \mathrm{C}\right)$. Harvested algae were centrifuged at $5000 \mathrm{rpm}$ to separate the algal cells from the growth medium and were then resuspended in an $\mathrm{N}$ - and P-free basal medium. Algal $\mathrm{P}$ content was measured on dried and digested algal samples using the molybdate-blue ascor- bic acid method (APHA 1992). Algal C and N content were measured on dried samples with a CNS analyzer (Vario EL, Elementar Incorporated, Mt. Laurel, New Jersey, USA). Reduced $\mathrm{P}$ supply in the algal media caused Scenedesmus to elevate both cellular N:P and C:P ratios (Table 1). Spore doses were created by homogenizing several infected Daphnia and counting the resulting spore concentration with a haemocytometer under a light microscope. We chose to infect Daphnia with a spore dose (16000 spores) that was previously found to result in intermediate $(60-80 \%)$ infection rates (Regoes et al. 2003). Daphnia were exposed to spores for six days, after which they were transferred to fresh pathogen-free water. During this initial infective period, animals were fed high quantities $(2 \mathrm{mg} \mathrm{C} / \mathrm{L})$ of algae of different food C:P ratios every second day. Thereafter, animals were fed higher quantities (4-6 mg C/L) of a Prich algae $(\mathrm{C}: \mathrm{P} \approx 100)$ every other day to ensure high survival and prevent food limitation through the experimental period. After day 14, animals were checked daily for signs of infection, which include sustained sterility, gigantism, and a deep red pigmentation (Ebert 2005). After day 21, remaining animals were dissected and examined under a microscope to verify the presence/absence of the bacterial infection. Simple linear regression was used to determine the relationship between daphnid infection rate and food C:P ratios.

\section{Spore production responses to food quality}

We measured the number of spores produced in individual Daphnia grown in the laboratory and provided food of different C:P ratios (100-700) typical of the range found in natural lakes (Guildford and Hecky 2000). On the first day of the experiment, 280 Daphnia neonates were collected and assigned either into infected (240 neonates) or control (40 neonates) treatments. Neonates were placed into individual tubes and exposed to one dose of 75000 Pasteuria spores for six days and provided a fixed quantity $(2 \mathrm{mg} \mathrm{C} / \mathrm{L})$ of $\mathrm{P}$ rich food every other day. This higher spore dose was chosen to ensure a very high (90-95\%) infection rate of Daphnia (Regoes et al. 2003). After this infection period, animals were placed into one of seven different food C:P ratio treatment levels. Algae were grown in media having different $\mathrm{P}$ concentrations as described above. Animals were fed food of their respective C:P treatment at high quantities $(>4 \mathrm{mg} \mathrm{C} / \mathrm{L})$ every other day for the following 20 days. On the final day, one-half of the animals were saved frozen until analyzed for the number of spores. Spores were counted using a haemocytometer after thawed animals were homogenized with a pestle (Regoes et al. 2003). The remaining animals were dried for 24 hours and weighed on a microbalance to determine their final dry mass. Responses of bacterial spore production (total number and density) to food quality were assessed with a single-factor ANOVA given the apparent nonlinear relationship between these two variables. 
FIG. 1. Infection rates of Daphnia by the pathogenic bacterium, Pasteuria ramosa, in animals consuming different algal C:P ratios. Note that all ratios are based on molar units; error bars show $95 \%$ CI.

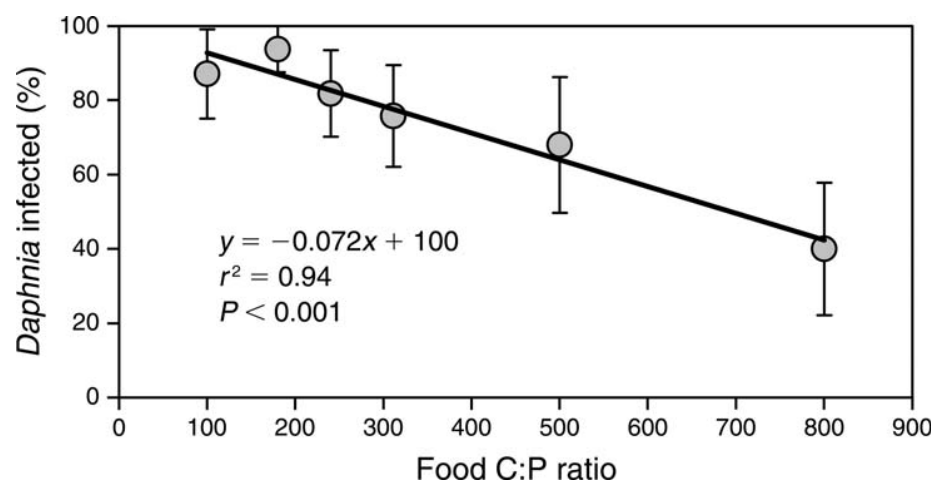

\section{Host responses to infection}

Host reproductive effort was measured for uninfected control Daphnia and animals infected with 75000 Pasteuria spores. This spore dose was chosen to ensure a very high (90-95\%) infection rate of Daphnia (Regoes et al. 2003). Each food $\times$ infection treatment combination started the experiment with 25-50 animals. Animals were transferred into fresh pathogen-free water after six days of spore exposure. Throughout the experiment, animals were fed high quantities of algae $(>4 \mathrm{mg} \mathrm{C} / \mathrm{L})$ having different C:P ratios (100-1200) every other day to prevent effects of low food quantity. This range of $\mathrm{C}: \mathrm{P}$ ratios is somewhat wider than normally seen in natural lakes (Guildford and Hecky 2000) but ensured that treatment Daphnia experienced widely contrasting P nutrition. The number of neonates produced from each Daphnia was recorded daily for the course of 30 days. This experiment was repeated three times to increase the number of treatment levels and to encompass a wider range of food C:P ratios. For all experiments, algae were grown as previously described under contrasting $\mathrm{P}$ supply. Offspring production was log-transformed to linearize its relationship with food C:P ratios. We used piecewise regressions, fitted in SigmaPlot, Version 10 (Systat Software Incorporated, San Jose, California, USA), to examine the relationship between food C:P ratios and offspring production in infected Daphnia.

\section{Results And Discussion}

Infectious disease is initiated by the successful colonization of the host by an invading pathogen. Infection rate (i.e., the likelihood that an individual host becomes infected) depends upon many factors that include the dose of infectious agents (Hochberg 1998, Regoes et al. 2003), host-pathogen specificity (Stirnadel and Ebert 1997), and ambient environmental conditions (Mitchell et al. 2005). We observed a strong effect of food $\mathrm{P}$ content on the infection rate of this invertebrate host (Fig. 1). Infection rate was negatively related to food C:P ratios with more than twice the number of infected individuals occurring in the P-rich foods compared to the P-poor foods (Fig. 1).

Potential explanations for lower infection rates in Daphnia consuming P-poor algal foods include: (1)
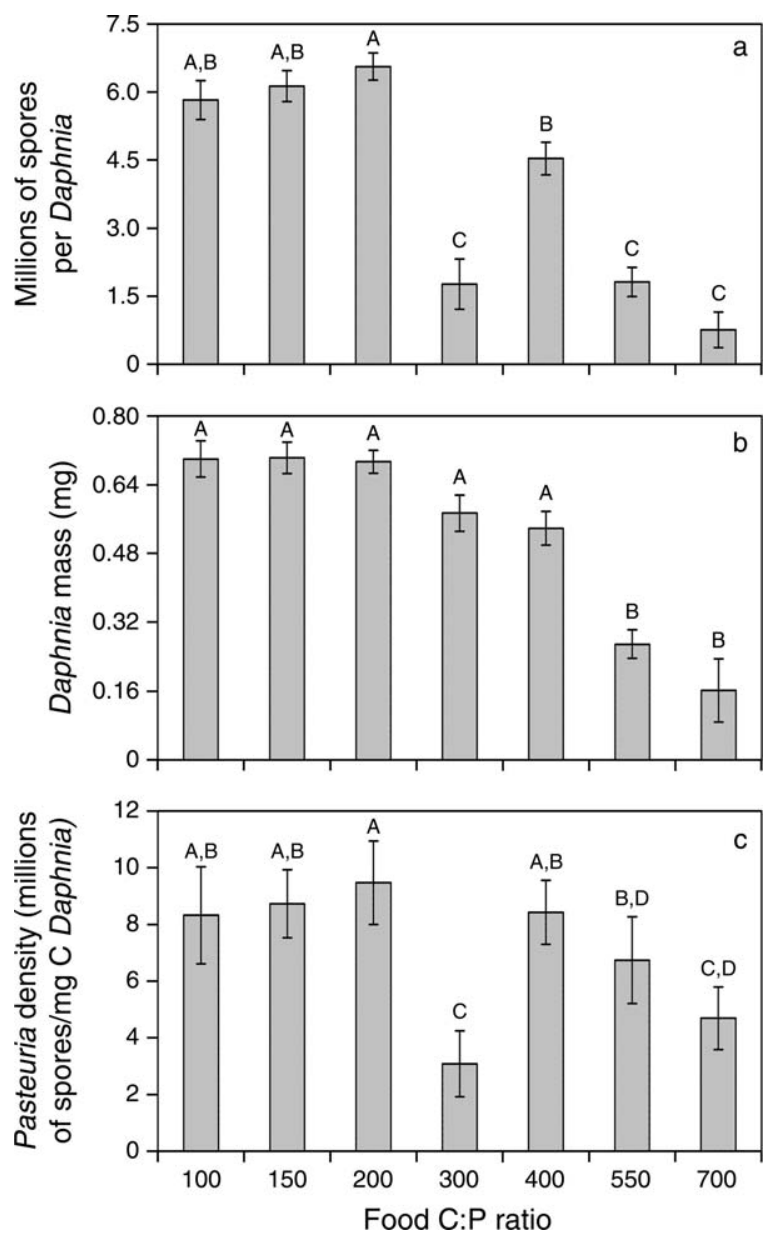

FIG. 2. (a) Number of Pasteuria spores in infected Daphnia magna provided algal food of different C:P ratios. (b) Body mass of Daphnia consuming different food C:P ratios. (c) Density of Pasteuria spores per milligram of carbon in the Daphnia bodies. In all three cases, a significant treatment effect $(P<0.001)$ of food C:P ratios was found using single-factor ANOVA. All data are given as mean $\pm \mathrm{SD}$; different letters above bars denote significant differences $(P<0.05)$ among treatment levels as determined by a Fisher-Hayter test (Kirk 1995). Note that all ratios are based on molar units. 

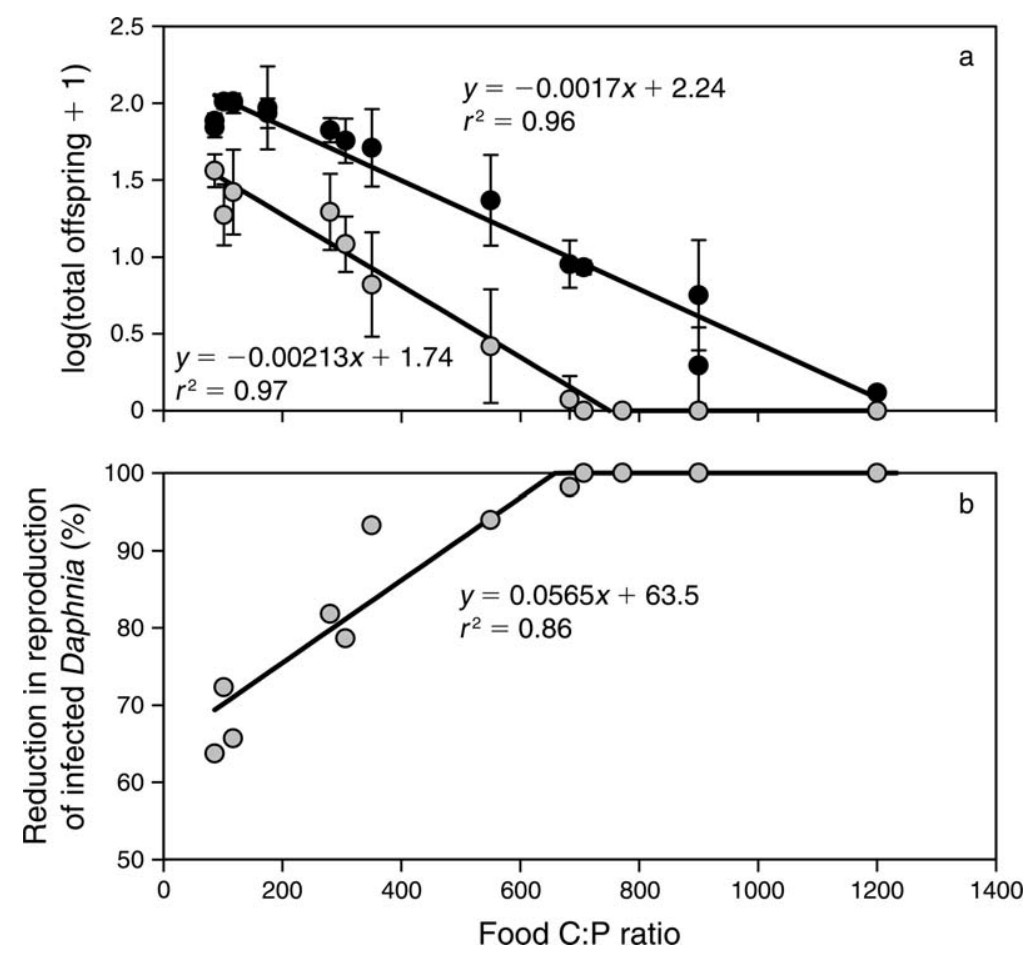

FIG. 3. (a) Log-transformed total number of neonates (mean \pm SD) born over 30 days to uninfected (black circles) and infected (gray circles) Daphnia magna provided algal food of different C:P ratios. Each point represents the average offspring production of 8-20 individuals. (b) Percentage reduction in offspring production of Daphnia infected by bacteria compared to uninfected individuals. Note that all ratios are based on molar units and, in both piecewise regressions, the slope of the regression line beyond the break point was not significantly different from zero.

reduced food intake and thus less spore exposure in Plimited Daphnia; (2) reduced gut residence time of particles and thus less time for spores to attach to the gut lining; and (3) reduced growth rates of bacterial vegetative cells. The first two explanations would be supported if Daphnia feeding rates and/or digestion dynamics were sensitive to their food C:P ratios. However, feeding rates and digestive tract turnover rate of Daphnia appear to be relatively insensitive to changes in food C:P ratios (Darchambeau 2005, Darchambeau and Thys 2005). As such, it seems unlikely that the observed decrease in infection rates of Daphnia consuming P-poor food is principally caused by changes in daphnid feeding. An alternative explanation is that lower infection rates resulted from lower growth rates of Pasteuria ramosa within these animals. This direct effect of host P nutrition would be consistent with the known coupling of $\mathrm{P}$ supply rates, ribosomal RNA content, and bacterial growth rates (Vadstein 2000, Elser et al. 2003).

The within-host growth rate of the pathogen is also reflected by the number of reproductive propagules (i.e., endospores) produced per host. We measured the number of bacterial spores produced in individual Daphnia consuming food of contrasting elemental quality. Spore production was significantly affected by algal food C:P ratios consumed by Daphnia (Fig. 2). We found the highest number of spores in Daphnia consuming P-rich algal foods, while the fewest spores were recorded in animals receiving algae having intermediate and very low $\mathrm{P}$ content. Increased spore numbers in the Daphnia consuming P-rich food resulted primarily from the greater mass of these animals (Fig. 2). Direct P limitation of Daphnia growth, which yields smaller animals, thus strongly reduces the total yield of the pathogen. We also found food $\mathrm{P}$ content caused relatively limited changes in the spore density in Daphnia bodies except for animals consuming algal food having C:P ratios of 300 and 700 (Fig. 2). While it is unclear why an especially low spore density was found in animals consuming food C:P ratios of 300 , the low spore densities observed in the most P-limited Daphnia suggests that poor host nutrition may constrain bacterial spore production. However, additional experimental study is needed to better determine how and why bacterial spore production relates to low $\mathrm{P}$ content in the host's diet.

Host responses to infection vary widely but include increased mortality, reduced reproduction, and changes in behavior (Sorensen and Minchella 1998, Sandland and Minchella 2003, Ebert 2005). We quantified how pathogen effects on host reproduction respond to changes in elemental food quality. Infection reduced total offspring production from Daphnia regardless of 
the C:P ratios in the algal food (Fig. 3a). However, there was an interaction between food quality and infection on Daphnia reproduction, which is evident by the increased reproductive losses caused by bacterial castration at higher food C:P ratios (Fig. 3b). This increased pathogen virulence on reproduction from hosts consuming high food C:P ratios is consistent with our hypothesis that a P-poor diet alters the nature of the interaction between the host and its bacterial parasite.

Our results show that elemental food quality can have strong effects on a bacterial pathogen infecting a common aquatic invertebrate. It appears that shortterm exposure to elementally imbalanced food may provide a competitive edge to the host and thus lower the within-host fitness of the pathogen. On the other hand, we also found the virulence of pathogenic bacteria on host reproduction to be increased in Daphnia consuming P-poor algal food. Consequently, while there may be potential value in the manipulation of elemental nutrition to treat and/or ameliorate pathogenic infections, the value of this approach would need to be weighed against increases in the virulence of the pathogen and/or the direct negative effects of nutrient limitation on the growth, reproduction, and survival of the host itself.

These results have important implications for our understanding of infectious disease in natural zooplankton communities. The changes in infection rates and spore production found here within one single daphnid generation would alter the likelihood of pathogenic infections in subsequent generations. Fewer infections and reduced spore production in P-limited hosts would decrease the spore dose confronted by the next generation of Daphnia and thereby lead to even lower infection rates. Coupled with higher mortality rates and lower population densities of the P-limited hosts, stoichiometric constraints on pathogens could dramatically reduce the frequency and severity of disease outbreaks in chronically nutrient-poor ecosystems.

On the other hand, nutrient-rich algae (e.g., C:P ratios $\sim 100-300$ by moles) are a prominent feature of eutrophic lake ecosystems (Elser et al. 2000, Guildford and Hecky 2000). In such ecosystems, the relaxation of stoichiometric constraints on pathogen infection and proliferation would be expected to contribute to more frequent and intense pathogen epidemics in lacustrine zooplankton communities. Eutrophication has been suggested to be an important driver of elevated parasitic infections in amphibians (Johnson and Chase 2004) and has been found to influence a wide variety of other aquatic host-pathogen systems (Barber et al. 2001, Danovaro et al. 2003, Limpens et al. 2003). Our results show host and pathogen nutrition may contribute to these relationships between infectious disease epidemics and excessive nutrient loading in aquatic ecosystems, which is a widespread and pervasive problem for both inland and coastal waters (Carpenter et al. 1998, Smith 2003, Schindler 2006).

\section{ACKNOWLedgments}

We thank H. Foy, C. Hibbert, M. Kingsbury, S. McCarthy, and D. Woolnough for their assistance with the experiments. This work was supported by grants from the Natural Sciences and Engineering Research Council of Canada and Trent University.

\section{Literature Cited}

APHA. 1992. Standard methods for the examination of water and wastewater. 18th edition. American Public Health Association, Washington, D.C., USA.

Barber, R. T., A. K. Hilting, and M. L. Hayes. 2001. The changing health of coral reefs. Human and Ecological Risk Assessment 7:1255-1270.

Calder, P. C., and A. A. Jackson. 2000. Undernutrition, infection and immune function. Nutrition Research Reviews 13:3-29.

Carpenter, S. R., N. F. Caraco, D. L. Correll, R. W. Howarth, A. N. Sharpley, and V. H. Smith. 1998. Nonpoint pollution of surface waters with phosphorus and nitrogen. Ecological Applications 8:559-568.

Danovaro, R., M. Armeni, C. Corinaldesi, and M. L. Mei. 2003. Viruses and marine pollution. Marine Pollution Bulletin 46:301-304.

Darchambeau, F. 2005. Filtration and digestion responses of an elementally homeostatic consumer to changes in food quality: a predictive model. Oikos 111:322-336.

Darchambeau, F., and I. Thys. 2005. In situ filtration responses of Daphnia galeata to changes in food quality. Journal of Plankton Research 27:227-236.

Ebert, D. 2005. Ecology, epidemiology, and evolution of parasitism in Daphnia. U.S. National Library of Medicine, National Center for Biotechnology Information Bethesda, Maryland, USA. 〈http://www.ncbi.nlm.nih.gov/entrez/query. fcgi?db=Books $\rangle$

Elser, J. J., K. Archaya, M. Kyle, J. Cotner, W. Makino, T. Markow, T. Watts, S. Hobbie, W. Fagan, J. Schade, J. Hood, and R. W. Sterner. 2003. Growth rate-stoichiometry couplings in diverse biota. Ecology Letters 6:936-943.

Elser, J. J., W. F. Fagan, R. F. Denno, D. R. Dobberfuhl, A. Folarin, A. Huberty, S. Interlandi, S. S. Kilham, E. McCauley, K. L. Schulz, E. H. Siemann, and R. W. Sterner. 2000. Nutritional constraints in terrestrial and freshwater food webs. Nature 408:578-580.

Frost, P. C., J. P. Benstead, W. F. Cross, H. Hillebrand, J. H. Larson, M. A. Xenopoulos, and T. Yoshida. 2006. Threshold elemental ratios of carbon and phosphorus in aquatic consumers. Ecology Letters 9:774-779.

Frost, P. C., M. A. Evans-White, Z. V. Finkel, T. C. Jensen, and V. Matzek. 2005. Are you what you eat? Physiological constraints on organismal stoichiometry in an elementally imbalanced world. Oikos 109:18-28.

Guildford, S. J., and R. E. Hecky. 2000. Total nitrogen, total phosphorus, and nutrient limitation in lakes and oceans: Is there a common relationship? Limnology and Oceanography 45:1213-1223.

Hochberg, M. E. 1998. Establishing genetic correlations involving parasite virulence. Evolution 52:1865-1868.

Johnson, P. T. J., and J. M. Chase. 2004. Parasites in the food web: linking amphibian malformations and aquatic eutrophication. Ecology Letters 7:521-526.

Kegley, E. B., J. W. Spears, and S. K. Auman. 2001. Dietary phosphorus and an inflammatory challenge affect performance and immune function of weanling pigs. Journal of Animal Science 79:413-419.

Kilham, S. S., D. A. Kreeger, S. G. Lynn, C. E. Goulden, and L. Herrera. 1998. COMBO: a defined freshwater culture medium for algae and zooplankton. Hydrobiologia 377:147159. 
Kirk, R. E. 1995. Experimental design: procedures for the behavioral sciences. Thomson-Brooks/Cole, Pacific Grove, California, USA.

Limpens, J., J. Raymakers, J. Baar, F. Berendse, and J. D. Zijlstra. 2003. The interaction between epiphytic algae, a parasitic fungus and Sphagnum as affected by N and P. Oikos 103:59-68.

Mitchell, S. E., E. S. Rogers, T. J. Little, and A. F. Read. 2005 Host-parasite and genotype-by-environment interactions: Temperature modifies potential for selection by a sterilizing pathogen. Evolution 59:70-80.

Regoes, R. R., J. W. Hottinger, L. Sygnarski, and D. Ebert. 2003. The infection rate of Daphnia magna by Pasteuria ramosa conforms with the mass-action principle. Epidemiology and Infection 131:957-966.

Sandland, G. J., and D. J. Minchella. 2003. Effects of diet and Echinostoma revolutum infection on energy allocation patterns in juvenile Lymnaea elodes snails. Oecologia 134:479486.
Schindler, D. W. 2006. Recent advances in the understanding and management of eutrophication. Limnology and Oceanography $51: 356-363$.

Smith, V. H. 2003. Eutrophication of freshwater and marine ecosystems: a global problem. Environmental Science and Pollution Research 10:126-139.

Sorensen, R. E., and D. J. Minchella. 1998. Parasite influences on host life history: Echinostoma revolutum parasitism of Lymnaea elodes snails. Oecologia 115:188-195.

Sterner, R. W., and J. J. Elser. 2002. Ecological stoichiometry: the biology of elements from molecules to the biosphere. Princeton University Press, Princeton, New Jersey, USA.

Stirnadel, H. A., and D. Ebert. 1997. Prevalence, host specificity and impact on host fecundity of microparasites and epibionts in three sympatric Daphnia species. Journal of Animal Ecology 66:212-222.

Vadstein, O. 2000. Heterotrophic, planktonic bacteria and cycling of phosphorus: phosphorus requirements, competitive ability, and food web interactions. Advances in Microbial Ecology 16:115-167. 